\title{
The Vibration of a Beam under a Traversing Load
}

\author{
by \\ Kan-Chen (Jane) Wu \\ Bachelor of Engineering, Ryerson 2003
}

\author{
A report \\ presented to Ryerson University \\ in partial fulfillment of the \\ requirements for the degree of \\ Master of Engineering \\ in the Program of \\ Mechanical Engineering \\ Toronto, Ontario, Canada, 2005 \\ (C) Kan-Chen (Jane) Wu, 2005
}


UMI Number: EC53474

\section{INFORMATION TO USERS}

The quality of this reproduction is dependent upon the quality of the copy submitted. Broken or indistinct print, colored or poor quality illustrations and photographs, print bleed-through, substandard margins, and improper alignment can adversely affect reproduction.

In the unlikely event that the author did not send a complete manuscript and there are missing pages, these will be noted. Also, if unauthorized copyright material had to be removed, a note will indicate the deletion.

\section{$\mathrm{UMI}^{\circ}$}

UMI Microform EC53474

Copyright 2009 by ProQuest LLC

All rights reserved. This microform edition is protected against unauthorized copying under Title 17, United States Code.

\section{ProQuest LLC}

789 East Eisenhower Parkway

P.O. Box 1346

Ann Arbor, MI 48106-1346 


\section{Author's Declaration}

I hereby declare that I am the sole author of this thesis.

I authorize Ryerson University to lend this thesis to other institutions or individuals for the purpose of scholarly research.

I further authorize Ryerson University to reproduce this thesis by photocopying or by other means, in total or in part, at the request of other institutions or individuals for the purpose of scholar research. 


\begin{abstract}
The objective of this study is to investigate the response of an Euler-Bernoulli beam under a force or mass traversing with constant velocity. Simply-supported and clampedclamped boundary conditions are considered. The linear strain-displacement scenario is applied to both boundary conditions, while the von Kármán nonlinear scenario is applied only to the former boundary condition. The governing equation of motion is derived via the extended Hamilton's principle. Simulations are performed with the fourth-order Runge-Kutta method via Matlab software. The equation of motion is first validated and then used to investigate the effects of the beam second moment of area, the magnitude of the traversing velocity, and centrifugal and gyroscopic forces.
\end{abstract}




\section{Acknowledgements}

I would like to thank Dr. Donatus Oguamanam for his guidance, encouragement and support throughout the duration of this project. I would also like to thank my parents for their love and support. 


\section{Table of Contents}

Author's Declaration ........................................................................................................................

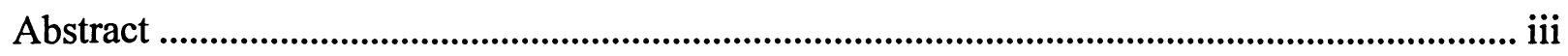

Acknowledgements ........................................................................................................................

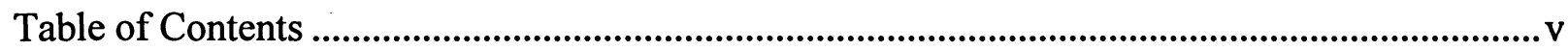

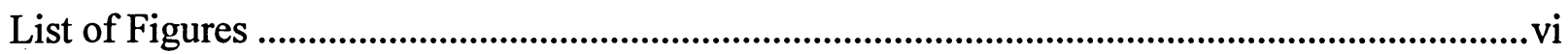

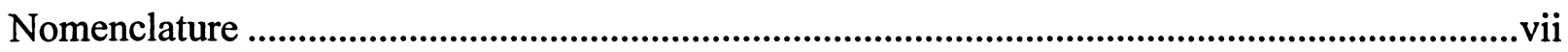

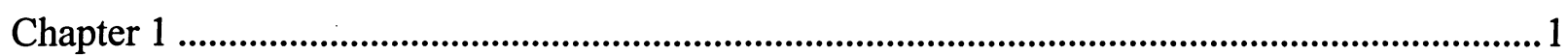

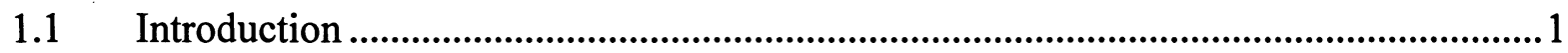

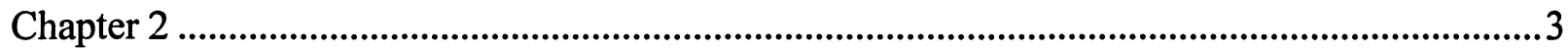

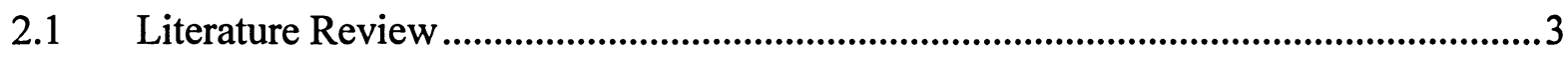

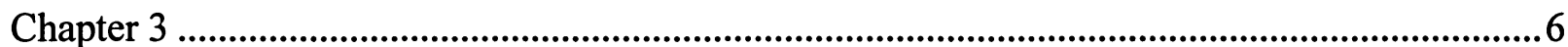

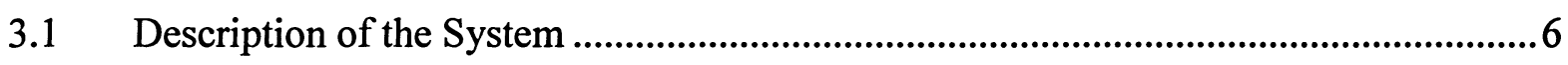

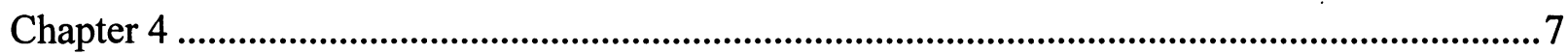

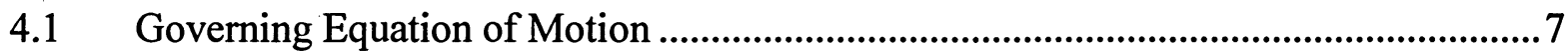

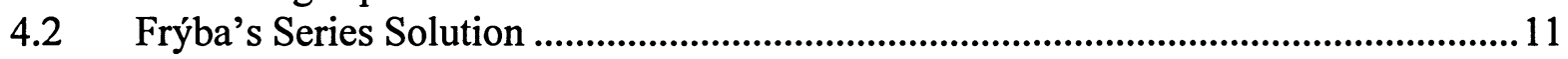

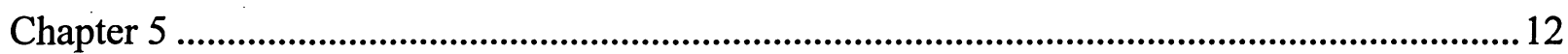

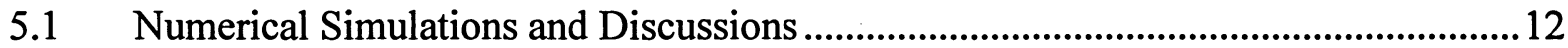

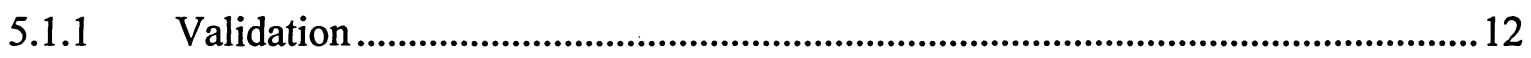

5.1.2 Effect of Beam Second Moment of Area .........................................................17

5.1.3 Effect of Traversing Velocity ................................................................................20

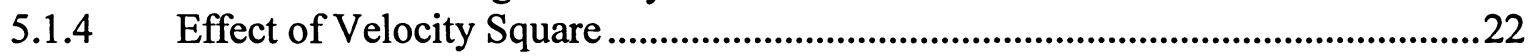

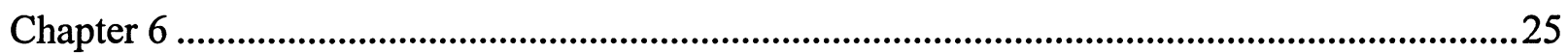

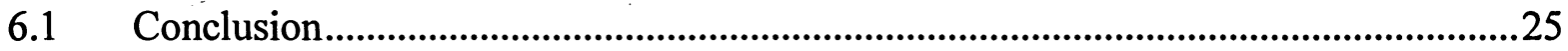

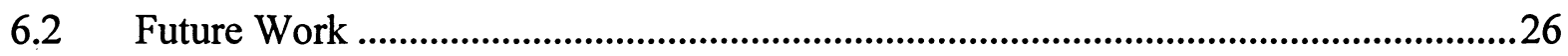

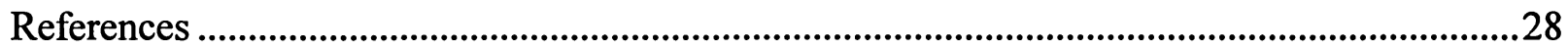




\section{List of Figures}

Figure 1 Euler-Bernoulli beam with a traversing load ................................................................6

Figure 2 The displacement of a force traversing a simply-supported beam ...............................13

Figure 3 The displacement of a force/mass traversing a simply-supported beam ......................... 14

Figure 4 The displacement of the traversing load on a clamped-clamped beam ...........................15

Figure 5 Effect of the representation of the gyroscopic for a simply-supported beam ..................16

Figure 6 Effect of the representation of the gyroscopic forces for a clamped-clamped beam....16

Figure 7 The linear displacement of the traversing mass on a simply-supported beam ...............17

Figure 8 The displacement of a traversing mass on a clamped-clamped beam ............................18

Figure 9 The nonlinear displacement of a traversing force on a simply-supported beam ...........19

Figure 10 The nonlinear displacement of a traversing mass on a simply-supported beam..........19

Figure 11 The linear displacement of a traversing mass on a simply-supported beam.................21

Figure 12 The linear displacement of a traversing mass on a clamped-clamped beam ..............21

Figure 13 The nonlinear displacement of a traversing mass on a simply-supported beam..........22

Figure 14 The linear displacement of a traversing mass on a simply-supported beam.................23

Figure 15 The nonlinear displacement of a traversing mass on a simply-supported beam..........24 


\section{Nomenclature}

$\overrightarrow{\mathfrak{r}}_{\mathrm{b}} \quad$ Position vector of differential beam element

$\vec{r}_{\mathrm{m}} \quad$ Position vector of traversing load

$\hat{\mathrm{n}}_{\mathrm{x}}, \hat{\mathrm{n}}_{\mathrm{y}}, \hat{\mathrm{n}}_{\mathrm{z}} \quad$ Unit vectors along the reference axes

A Beam cross-sectional area

b Width of the beam cross section

E Young's modulus

f Traversing force

g Gravitational constant

$\mathrm{h} \quad$ Height of the beam cross section

I Second moment of area

j Mode number

$\mathrm{L} \quad$ Beam length

$\mathrm{m} \quad$ Traversing mass

q Column vector of an undetermined parameter

$\mathrm{T} \quad$ Kinetic energy

$\mathrm{U}_{\mathrm{b}} \quad$ Strain energy of the beam

$\mathrm{w}(\mathrm{x}, \mathrm{t}) \quad$ Dimensional displacement at position $\mathrm{x}$ at time $\mathrm{t}$

$\mathrm{w}(\xi, \mathrm{t}) \quad$ Nondimensional displacement at position $\xi$ at time $\mathrm{t}$

$\mathrm{W}_{\mathrm{g}} \quad$ Work done by the traversing load

$\mathrm{W}_{\mathrm{i}}$. Eigenfunction

$\mathrm{w}_{\mathrm{m}} \quad$ Dimensional displacement of the load at position $\mathrm{x}_{\mathrm{m}}$ at time $\mathrm{t}$

$\mathrm{w}_{0} \quad$ Static deflection of the beam

$\mathrm{x} \quad$ Dimensional position on the beam

$\mathrm{x}_{\mathrm{m}} \quad$ Dimensional position of the mass on the beam

\section{Greek Letters}

$\begin{array}{ll}\dot{\xi}_{\mathrm{cr}} & \text { Nondimensional critical velocity of the traversing load } \\ \dot{\xi} & \text { Nondimensional velocity of the traversing load } \\ \xi & \text { Nondimensional position } \\ \alpha & \text { Velocity ratio } \\ \alpha_{\mathrm{b}}, \alpha_{\mathrm{NL}}, \alpha_{\mathrm{fm}} & \text { Boolean variable } \\ \varepsilon_{\mathrm{xx}} & \text { von Kármán strain } \\ \lambda & \text { Frequency } \\ \rho & \text { Beam density } \\ \omega & \text { Circular frequency }\end{array}$




\section{Chapter 1}

\subsection{Introduction}

The behaviour of structures under any moving load has always been a problem that interests many scientists and engineers. The applications of such dynamic systems can be seen in many places, such as highways, railroad tracks or bridges. Since these structures are constantly under dynamic loading, many structural problems are the result of vibration. Therefore, vibration is an important issue that needs to be explored in detail.

There are many types of scenarios that can simulate the behaviour of structures under moving loads. In this project, the behaviour of a beam is investigated under different assumptions and factors. The system consists of an Euler-Bernoulli beam which is under a moving load. The load is assumed to be a concentrated force or mass. Simply-supported and clamped-clamped boundary conditions are applied to the system. Both linear and nonlinear scenarios are included. In the linear scenario, both boundary conditions are considered. For the nonlinear scenario, only the simply-supported boundary condition is considered.

A literature review is presented in the next chapter, followed by the description and schematic of the beam model. The fourth chapter contains the derivation of the governing equation of motion. The equation of motion is solved via a fourth-order Runge-Kutta method with Matlab software. The fifth chapter concerns the numerical simulations and discussions. The governing equation of motion is validated by reproducing the results in the literature, and some inconsistencies are observed. Other effects on the system dynamics are studied, specifically, the effect of the second moment of area, followed by the traversing velocity and 
the influence of the velocity square term on the beam displacement. In the conclusion, summaries regarding the results and discussion presented in the numerical simulation are listed and suggestions for future work are outlined. 


\section{Chapter 2}

\subsection{Literature Review}

There are many published books and articles regarding beam-with-moving-load problems. It was initially studied by Stokes [1] in the 1800s. The book by Frýba [2] introduces the problem in a systematic fashion, starting from a simply-supported beam to more complex systems. The study by Rao [3] suggests that internal resonance depends on the ratio of the moving load mass to the beam mass. The gravitational effect on the moving load explains the external resonance. The equation of motion is solved by using the multiple scales method.

Atkin and Mofid's [4] study include other boundary conditions besides simplysupported. Hamada [5] applies double Laplace transformation with respect to both time and spatial variables to obtain a Fourier series representation of the forced vibration portion of the transient response in closed form. It is noted that the method is applicable only to a low velocity scenario. The convergence of the Fourier series is slow for high velocity problems.

Sadiku and Leipholz [6] use Green's function to develop the system equation. The differential equation is then converted into an integro-differential equation. This method can be applied to other boundary and loading conditions. The solution shows good accuracy and convergence. The main conclusion drawn by comparing the moving force and mass systems is that the peak displacement of the moving force solution is not necessarily higher than that of the moving mass case. 
Stanisic et al. [7] use both analytical and numerical methods. The analytical method is a modified version of the asymptotic method from nonlinear mechanics theory. The exact numerical method is a general procedure used to solve the ordinary differential equations with a singular coefficient. Results produced by both methods show good agreement. Another study conducted by Stanisic [8] later uses eigenfunction expansion in a series. The result is described as in "closed form", which is in the sense of fast convergence in comparison to numerical techniques. The results are produced with and without a convective term in the acceleration. It is shown that the eigenfunction method solution with the convective term is a match to the numerical solution in Ref. [7] at the onset of the simulation. As the mass moves on, the eigenfunction method solution is closer to the numerical solution if the convective term is excluded.

The Timoshenko beam model is used in the studies reported in Ref. [9-13]. There are assumptions made in the Euler-Bernoulli model which are relaxed in the Timoshenko model. The effects of rotatory inertia and transverse shear deformation are included in the governing equation. It is mention in Ref. [12] that the significance of the difference in the deflection resulting from using both beam theories increases with increasing moving mass traverse velocity.

The issue of moving load and beam separation is addressed in Ref. [9-10, 14]. The separation is detected through the monitoring of the contact force between the load and the beam. The contact force is a combination of the inertia of the mass, a centrifugal force, a Coriolis force, and gravity. There is also a time and velocity dependent force that is due to the 
deformation of the surface. The contact force is nonlinear and is usually presented as a concentrated force with a Dirac-delta function. This separation issue needs to be addressed if the velocity of the moving mass is high.

In Ref. [15-17], the moving mass problem is solved with a finite element method. The advantage of using this method is its adaptability to other variations of the system. Since the beam is discretized, the interpolation is going to affect some aspects of the problem. One error in the interpolation at a certain time step is going to affect the next time step [16]. 


\section{Chapter 3}

\subsection{Description of the System}

A diagram of the system is shown in Fig. 1. The origin of the system $O$ is on the lefthand-side (LHS) of the beam. The positive X-direction runs from the origin $\mathrm{O}$ toward the righthand-side (RHS) of the beam. The positive $\mathrm{Z}$ direction is pointing downward. The positive $\mathrm{Y}$ axis is the cross-product of the $\mathrm{Z}$ and $\mathrm{X}$ axes. The unit vectors along the $\mathrm{X}, \mathrm{Y}$, and $\mathrm{Z}$ axes are denoted by $\hat{n}_{x}, \hat{n}_{y}, \hat{n}_{z}$.

A travelling force, $\mathrm{f}$, or mass, $\mathrm{m}$, is moving from the point of origin $\mathrm{O}$ toward the RHS of the beam. The length, height, and width of the beam are $L, h$ and $b$, respectively. The Young's modulus of elasticity of the beam is denoted by E. The second moment of area and the density of the beam are represented as I and $\rho$, respectively, while A denotes the crosssectional area. The boundary condition for the beam is either simply-supported (SS) or clamped-clamped (CC). The displacement of the beam under the travelling load is shown in the figure as $w(x, t)$. The distance traveled by the moving load is denoted by $x_{m}$.

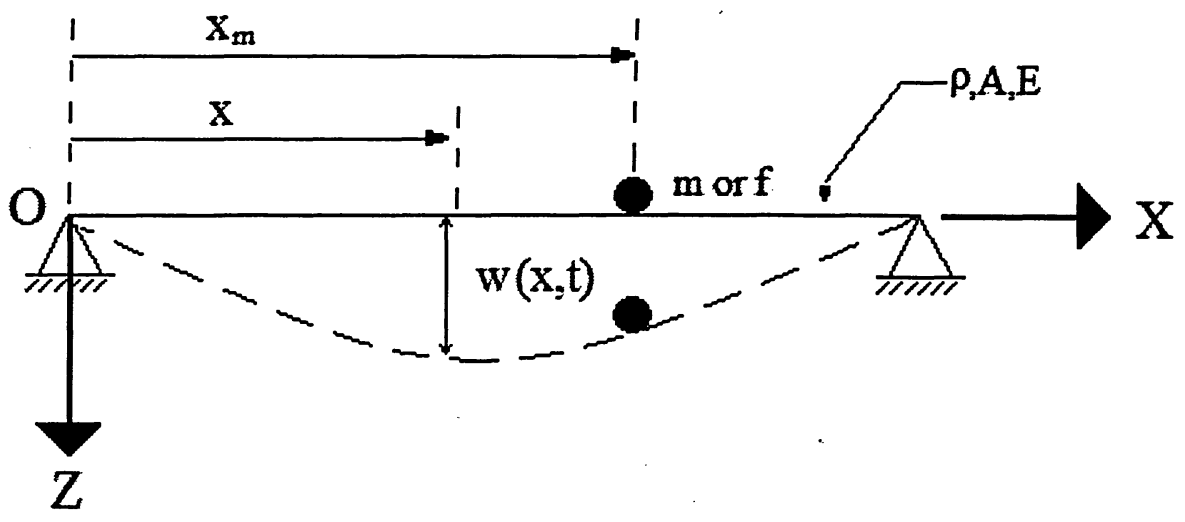

Figure 1 Euler-Bernoulli beam with a traversing load 


\section{Chapter 4}

\subsection{Governing Equation of Motion}

The equation of motion is derived by using the extended Hamilton's principle. The position vector, $\overrightarrow{\mathrm{r}}_{\mathrm{b}}$, of a differential beam element is written as

$$
\overrightarrow{\mathrm{r}}_{\mathrm{b}}=(\mathrm{x}+\overline{\mathrm{u}}) \hat{\mathrm{n}}_{\mathrm{x}}+(\mathrm{z}+\mathrm{w}(\mathrm{x}, \mathrm{t})) \hat{\mathrm{n}}_{\mathrm{z}}
$$

where $\overline{\mathrm{u}}$, the axial deformation, is given as

$$
\overline{\mathrm{u}}=-\mathrm{zw}^{\prime}(\mathrm{x}, \mathrm{t})
$$

The prime denotes partial differentiation with respect to the spatial variable, and the superposed dot represents partial differentiation with respect to the temporal variable, $\mathrm{t}$.

The position of the travelling load is written as

$$
\mathrm{r}_{\mathrm{m}}=\left(\mathrm{x}_{\mathrm{m}}+\overline{\mathrm{u}}\right) \hat{\mathrm{n}}_{\mathrm{x}}+\left(\mathrm{z}+\mathrm{w}\left(\mathrm{x}_{\mathrm{m}}, \mathrm{t}\right)\right) \hat{\mathrm{n}}_{\mathrm{z}}
$$

The axial deformation in Eqns. (1) and (2) are dropped later because the beam is modeled by the Euler-Bernoulli beam theory.

The kinetic energy of the system is contributed by the beam and the moving mass. The velocities required to formulate the kinetic energy equation are the derivatives of the position vectors, Eqns. (1) and (2). Thus, the kinetic energy, T, of the system can be written as

$$
\mathrm{T}=\frac{1}{2} \rho A \int_{0}^{\mathrm{L}} \dot{\mathrm{w}}^{2} \mathrm{dx}+\left.\alpha_{\mathrm{fm}} \frac{1}{2} \mathrm{~m}\left(\dot{\mathrm{w}}+\mathrm{w}^{\prime} \dot{\mathrm{w}}\right)^{2}\right|_{\mathrm{x}=\mathrm{x}_{\mathrm{m}}}
$$

$\alpha_{\mathrm{fm}}$ is a Boolean variable. Values of 0 or 1 are assigned to $\alpha_{\mathrm{fm}}$ when the traversing load is a force or mass, respectively.

The von Kármán strain displacement relationship can be written as

$$
\varepsilon_{\mathrm{xx}}=-\mathrm{z \textrm {w } ^ { \prime \prime }}+\frac{1}{2}\left(\mathrm{w}^{\prime}\right)^{2}
$$


The strain energy of the beam $U_{b}$ is written as

$$
\mathrm{U}_{\mathrm{b}}=\frac{1}{2} \mathrm{EI} \int_{0}^{\mathrm{L}}\left(\mathrm{w}^{\prime \prime}\right)^{2} \mathrm{dx}+\alpha_{\mathrm{b}} \frac{1}{8} \mathrm{EA} \int_{0}^{\mathrm{L}}\left(\mathrm{w}^{\prime}\right)^{4} \mathrm{dx}
$$

where $\alpha_{b}$ is a variable of either 0 or 1 to indicate a linear or nonlinear strain-displacement relation. Symmetry of the cross section is assumed.

The virtual work done by the traversing load is

$$
\partial \mathrm{W}_{\mathrm{g}}=\left.\left(\alpha_{\mathrm{fm}} \mathrm{mg}+\left(1-\alpha_{\mathrm{fm}}\right) \mathrm{f}\right) \partial \mathrm{w}\right|_{\mathrm{x}=\mathrm{x}_{\mathrm{m}}}
$$

The position of the beam is normalized by the length of the beam $\mathrm{L}$. Therefore, the normalized position will be noted as $\xi$ in all subsequent derivations.

The deflection of the beam $w(x, t)$ is expanded as the product of the length of the beam, a row vector calculated via the eigenfunction and a column vector of an undetermined parameter $q(t)$.

$$
\mathrm{w}(\xi, \mathrm{t})=\mathrm{L} \underline{\mathrm{W}}^{\mathrm{T}}(\xi) \underline{\mathrm{q}}(\mathrm{t})
$$

The eigenfunction for a simply supported beam is [18]

$$
\mathrm{W}_{\mathrm{i}}(\xi)=\sqrt{2} \sin \left(\lambda_{\mathrm{i}} \xi\right)
$$

where the nondimensional frequency $\lambda_{i}=\pi i$, for $i=1,2,3, \ldots$

For a clamped-clamped beam, the eigenfunction is [18]

$$
\mathrm{W}_{\mathrm{i}}(\xi)=\cosh \left(\lambda_{i} \xi\right)-\cos \left(\lambda_{i} \xi\right)-\sigma_{i}\left(\sinh \left(\lambda_{i} \xi\right)-\sin \left(\lambda_{i} \xi\right)\right)
$$

where

$$
\sigma_{i}=\frac{\cosh \lambda_{i} L-\cos \lambda_{i} L}{\sinh \lambda_{i} L-\sin \lambda_{i} L}
$$

and $\lambda_{i}$ are the zeros of the characteristic equation

$$
\cos \lambda_{\mathbf{i}} \mathrm{L} \cosh \lambda_{\mathbf{i}} \mathrm{L}=1
$$


Eqn. (8) is substituted in Eqns. (4), (6) and (7) and the resulting equations are used in the extended Hamilton's principle

$$
\int \delta\left(T-U_{b}\right) d t+\int \delta W_{g} d t=0
$$

Variation is taken over the undetermined parameter $\mathrm{q}(\mathrm{t})$ and, after some algebraic manipulation, yields the system of governing equation

$$
\begin{aligned}
& \left(\mathrm{M}+\alpha_{\mathrm{fm}} \mathrm{m}_{\mathrm{T}} \underline{\mathrm{W}}_{\mathrm{m}} \underline{\mathrm{W}}_{\mathrm{m}}^{\mathrm{T}}\right) \underline{\ddot{q}}+2 \alpha_{\mathrm{fm}} \mathrm{m}_{\mathrm{T}} \dot{\xi}_{\mathrm{m}} \mathrm{C}_{1} \dot{\mathrm{q}}+\left(\mathrm{K}_{1}+\alpha_{\mathrm{fm}} \mathrm{m}_{\mathrm{T}} \dot{\xi}_{\mathrm{m}}^{2} \mathrm{~K}_{2}\right. \\
& \left.+\alpha_{\mathrm{fm}} \mathrm{m}_{\mathrm{T}} \ddot{\xi}_{\mathrm{m}} \mathrm{K}_{3}+\alpha_{\mathrm{NL}} \frac{1}{3} \mathrm{~K}_{4}\right) \underline{\mathrm{q}}=\left(\alpha_{\mathrm{fm}} \mathrm{m}_{\mathrm{T}} \mathrm{g}_{\mathrm{n}}+\left(1-\alpha_{\mathrm{fm}}\right) \mathrm{f}_{\mathrm{T}}\right) \underline{\mathrm{W}}_{\mathrm{m}}
\end{aligned}
$$

where

$$
\begin{aligned}
& \mathrm{M} \equiv \int_{0}^{1} \underline{\mathrm{W}}^{\mathrm{T}} \mathrm{d} \xi \quad \mathrm{m}_{\mathrm{T}} \equiv \frac{\mathrm{m}}{\rho \mathrm{AL}} \mathrm{f}_{\mathrm{T}} \equiv \frac{\mathrm{m}}{\rho A L^{2}} \quad \mathrm{~g}_{\mathrm{n}}=\frac{\mathrm{g}}{\mathrm{L}} \\
& \mathrm{C}_{1}=\mathrm{K}_{3}=\underline{\mathrm{W}}_{\mathrm{m}} \underline{\mathrm{W}}_{\mathrm{m}}^{\prime \mathrm{T}} \quad \mathrm{K}_{1} \equiv \frac{\mathrm{EI}}{\rho A L^{4}} \int_{0}^{1} \underline{\mathrm{W}}^{\prime \prime} \underline{\mathrm{W}}^{\prime \prime \mathrm{T}} \mathrm{d} \xi \quad \mathrm{K}_{2}=\underline{\mathrm{W}}_{\mathrm{m}} \underline{\mathrm{W}}_{\mathrm{m}}^{\prime \prime \mathrm{T}} \\
& \mathrm{K}_{4} \equiv \frac{\mathrm{E}}{\rho \mathrm{L}^{2}} \int_{0}^{1}\left(\underline{\mathrm{Hq}}^{\mathrm{T}} \mathrm{H}+\frac{1}{2} \underline{q}^{\mathrm{T}} \mathrm{HqH}\right) \mathrm{d} \xi \quad \mathrm{H} \equiv \underline{\mathrm{W}}^{\prime} \underline{\mathrm{W}}^{\prime \mathrm{T}}
\end{aligned}
$$

The $\alpha_{\mathrm{NL}}$ will be 1 when the system is in a nonlinear scenario and 0 otherwise. $\mathrm{K}_{2}$ and $\mathrm{K}_{3}$ in Eqn. (14) contribute to the asymmetry in the stiffness matrix which represents the circulatory (centrifugal) forces. The asymmetry in the third term gives rise to gyroscopic (Coriolis) forces. In Ref. [19], $C_{1}$ is written as

$$
\frac{1}{2}\left(\underline{\mathrm{W}}_{\mathrm{m}} \underline{\mathrm{W}}_{\mathrm{m}}^{\prime \mathrm{T}}+\underline{\mathrm{W}}_{\mathrm{m}}^{\prime} \underline{\mathrm{W}}_{\mathrm{m}}^{\mathrm{T}}\right) \underline{\dot{\mathrm{q}}}
$$

which does not have the gyroscopic force since the matrix is symmetric. The consequence of such misrepresentation will be demonstrated later. 
Equation (14) is solved using the ordinary differential equation solver function ode45 of Matlab software. Its default error tolerance is $10^{-6}$. The interval of integration is the same as the time required for the force or mass to traversing through the whole beam span. The applied initial conditions are

$$
\underline{q}(0)=\underline{\dot{q}}(0)=0
$$




\subsection{Frýba's Series Solution}

The series solution of the deflection of the beam under a force is found in the text by Frýba [2]. The Euler-Bernoulli beam is used with a simply-supported boundary condition. There are two equations to consider. When the velocity ratio $\alpha$ is not equal to the mode number, $\mathrm{j}$, in the series, the deflection is calculated as

$$
w(x, t)=w_{o} \sum_{j=1}^{\infty} \sin \frac{j \pi x}{L} \frac{1}{j^{2}\left(j^{2}-\alpha^{2}\right)}\left(\sin j \omega t-\frac{\alpha}{j} \sin \omega_{(j)} t\right)
$$

In the case when the velocity ratio $\alpha$ is equal to a value $\mathrm{n}$ and it is also equal to the mode number $\mathrm{j}$, the displacement is then calculated as

$$
\begin{aligned}
w(x, t)= & w_{o} \frac{1}{2 n^{4}}(\sin n \omega t-n \omega t \cos n \omega t) \sin \frac{n \pi x}{L}+ \\
& w_{o} \sum_{j=1, j \neq n}^{\infty} \sin \frac{j \pi x}{L} \frac{1}{j^{2}\left(j^{2}-\alpha^{2}\right)}\left(\sin j \omega t-\frac{\alpha}{j} \sin \omega_{(j)} t\right)
\end{aligned}
$$

where

$$
\omega_{(j)}=j^{2} \pi^{2} \sqrt{\frac{E I}{L^{4} A \rho}} \text { and } \omega=\pi \dot{\xi}
$$

The displacement is depicted in the validation section and it is compared to the displacement calculated with Eqn. (14) in this study. 


\section{Chapter 5}

\subsection{Numerical Simulations and Discussions}

The geometric dimensions and material properties of the beam used in the simulation are identical to those in Ref. [6], unless specified otherwise. The length $L$ of the beam is $6 \mathrm{~m}$ and it has a square cross section with an area of $0.16 \mathrm{~m}^{2}$. The beam is made of a material whose Young's modulus $\mathrm{E}$ is $280 \mathrm{MPa}$ and the density $\rho$ is obtained from the ratio EI/ $\rho \mathrm{A}$, which is kept constant at $275.4408 \mathrm{~m}^{4} / \mathrm{s}^{2}$. The traversing force $\mathrm{f}_{\mathrm{T}}=0.2 / \mathrm{s}^{2}$ and the nondimensional traversing mass $\mathrm{m}_{\mathrm{T}}$ is 0.2 . While the governing equation, Eqn. (14), is for a traversing load in general motion, the results are presented for those cases while the load travels at a constant velocity; hence the acceleration term is ignored.

For clarity of presentation, the results and discussions are presented in four subsections.

\subsubsection{Validation}

Here, attempts are made to validate the model by comparing it with those found in the literature. The first investigation is a moving force scenario in which the force travels at a constant velocity of $6 \mathrm{~m} / \mathrm{s}$. The deflections of the beam under the force, $w(\xi, t)$, obtained with the present model and that obtained using Fryba's series solution [2] are depicted in Fig. 2. A good agreement is observed between the two results, with the latter providing a marginally higher peak deflection. 


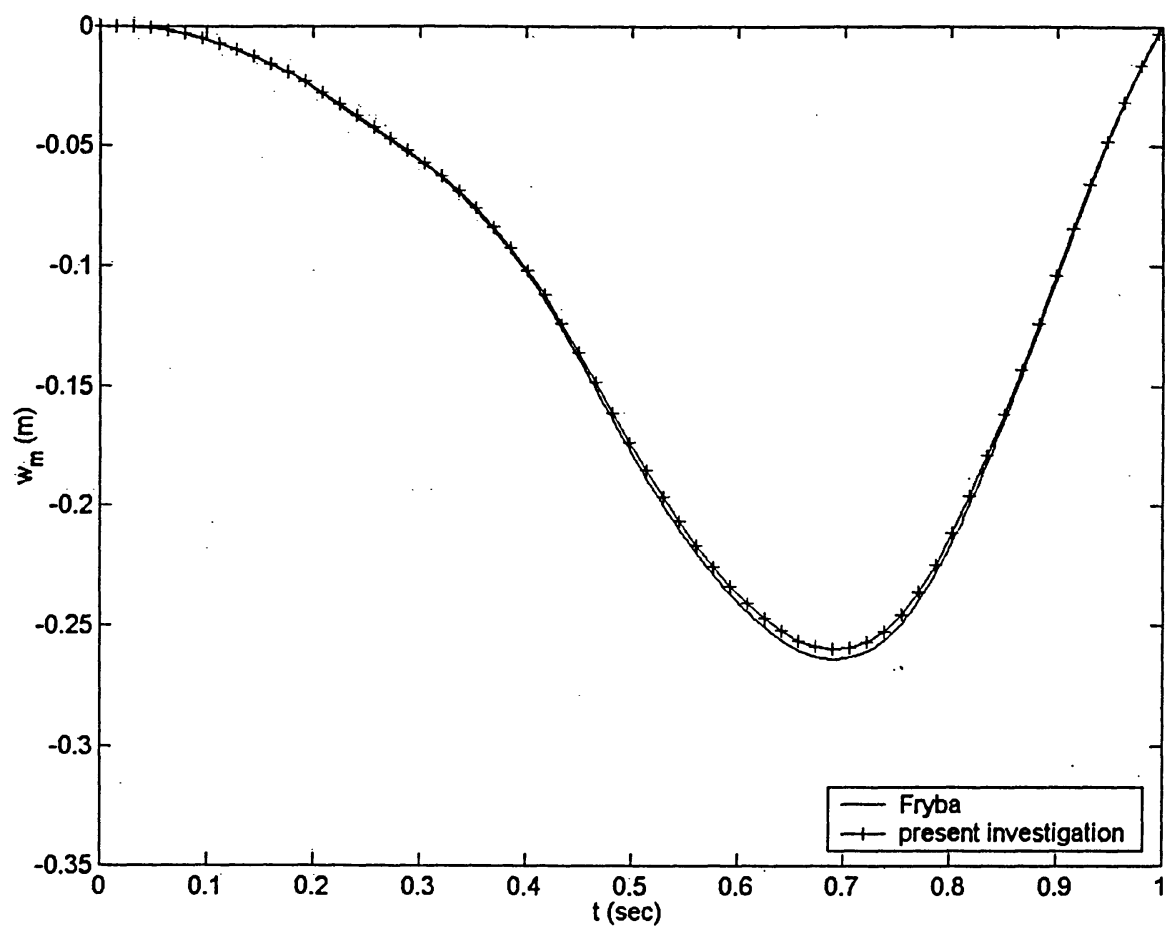

Figure 2 The displacement of a force traversing a simply-supported beam

Figure 3 is a reproduction of the results by Sadiku and Leipholz (see Fig. 3 in Ref. [6]) which are displacements of the traversing load. It involves a simply-supported beam traversed by a mass or force travelling at a constant velocity of $6 \mathrm{~m} / \mathrm{s}$. Four cases are investigated. The first case is a moving force scenario; it is the same scenario reported in Fig. 2. The second case is a moving mass scenario in which the convective terms in Eqn. (14) are ignored. Hence, the terms involving $\dot{\xi}$ and $\dot{\xi}^{2}$ are ignored. In the third case, a moving mass scenario is considered but the velocity square, $\dot{\xi}^{2}$, term is ignored. The fourth case is also a moving mass scenario, but includes all the terms in Eqn. (14).

A visual comparison with Fig. 3 of Ref. [6] and Fig. 2 of Ref. [20] shows that the result for the traversing force is in good agreement. The traversing mass result of Ref. [20] is in good 
agreement with the fourth case of the present study, as expected. However, that of Ref. [6] is in good agreement with only the third case of the present study. This is the case where the velocity square term $\dot{\xi}^{2}$ term is ignored. It is perhaps worth noting that the authors do not mention this assumption specifically, but it is not uncommon that the assumption is made in order to make the mathematics more tractable, for example in Stanisic [8].

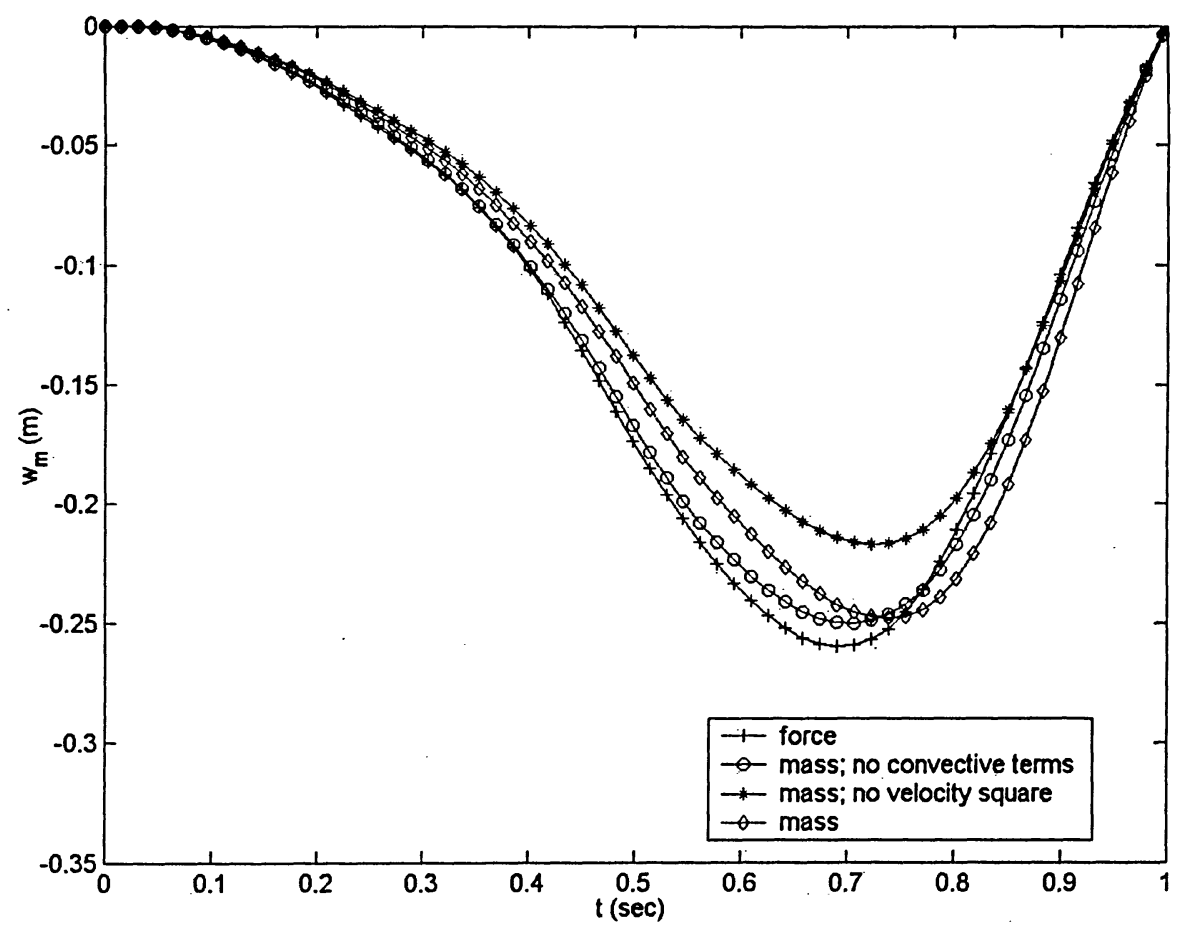

Figure 3 The displacement of a force/mass traversing a simply-supported beam

The aforementioned four cases are repeated for clamped-clamped beam boundary conditions and the results are depicted in Fig. 4. The traversing force result is in better agreement with that of Gbadeyan and Oni [20] (see Fig. 2) than Sadiku and Leipholz [6]. 


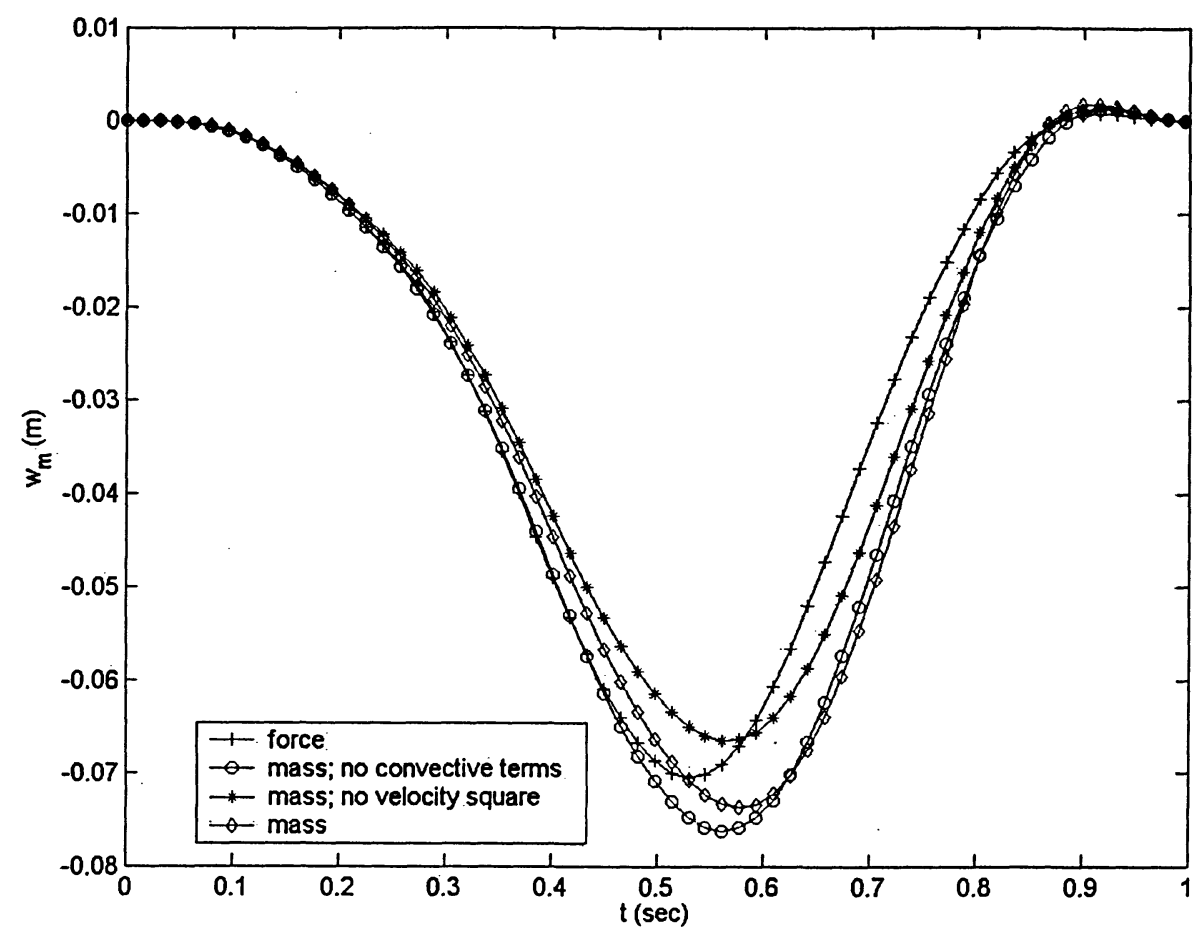

Figure 4 The displacement of the traversing load on a clamped-clamped beam

Again it is observed that the displacement of the traversing mass reported in Ref. [6] is not in agreement with both that of the present study and that of Gbadeyan and Oni Ref. [20]. However, there are slight differences between the result of the present study and that of Ref. [20] even though the peak displacements are approximately equal.

It is observed that the formulation by Lee [19] does nothave the gyroscopic forces term. The implication of this is investigated for both the simply-supported and clamped-clamped beam boundary conditions. The results are depicted in Figs. 5 and 6, respectively. It is observed that while the profiles of the displacement of the traversing mass are in good agreement, the exclusion of the gyroscopic forces always overestimates the peak displacement and generally predicts higher displacements about the 0.4 sec mark. 


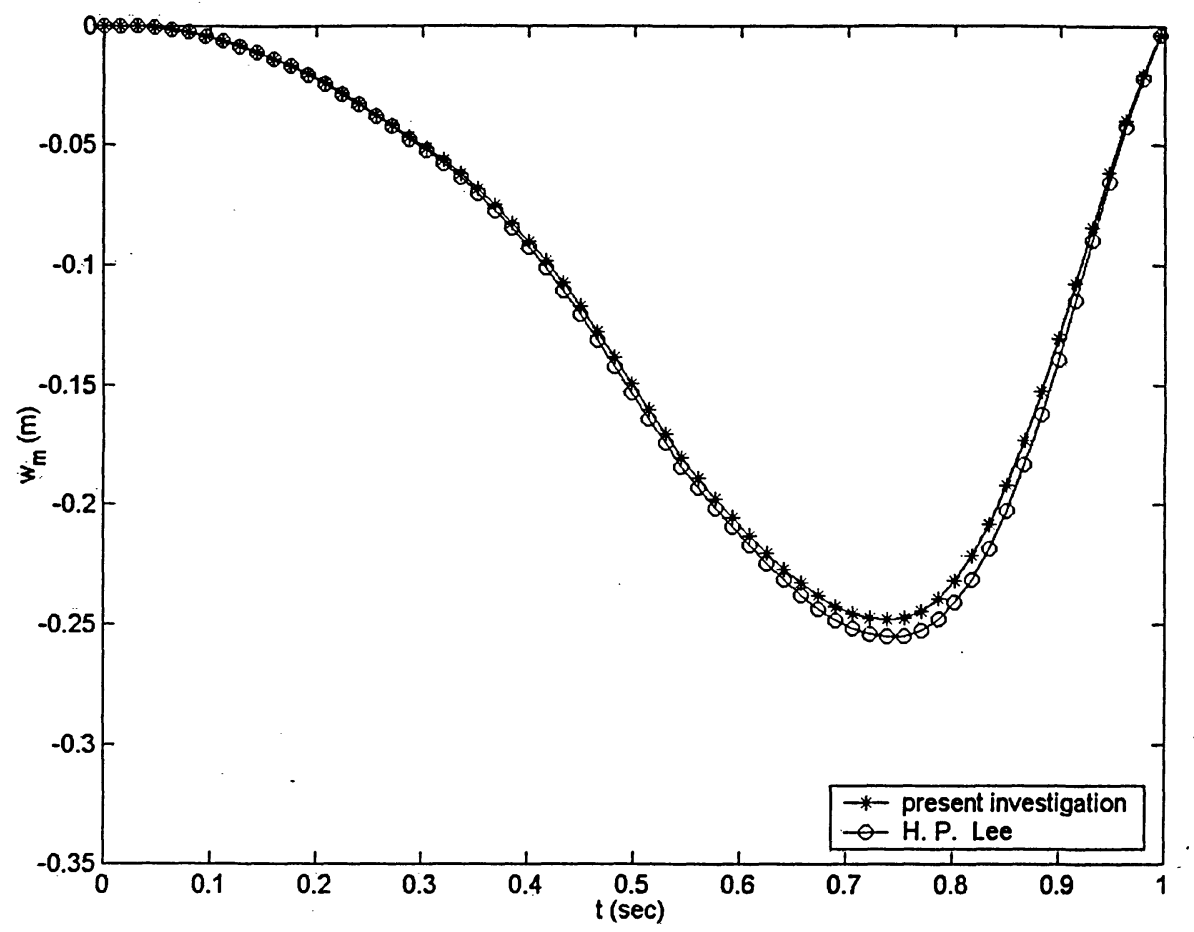

Figure 5 Effect of the representation of the gyroscopic for a simply-supported beam

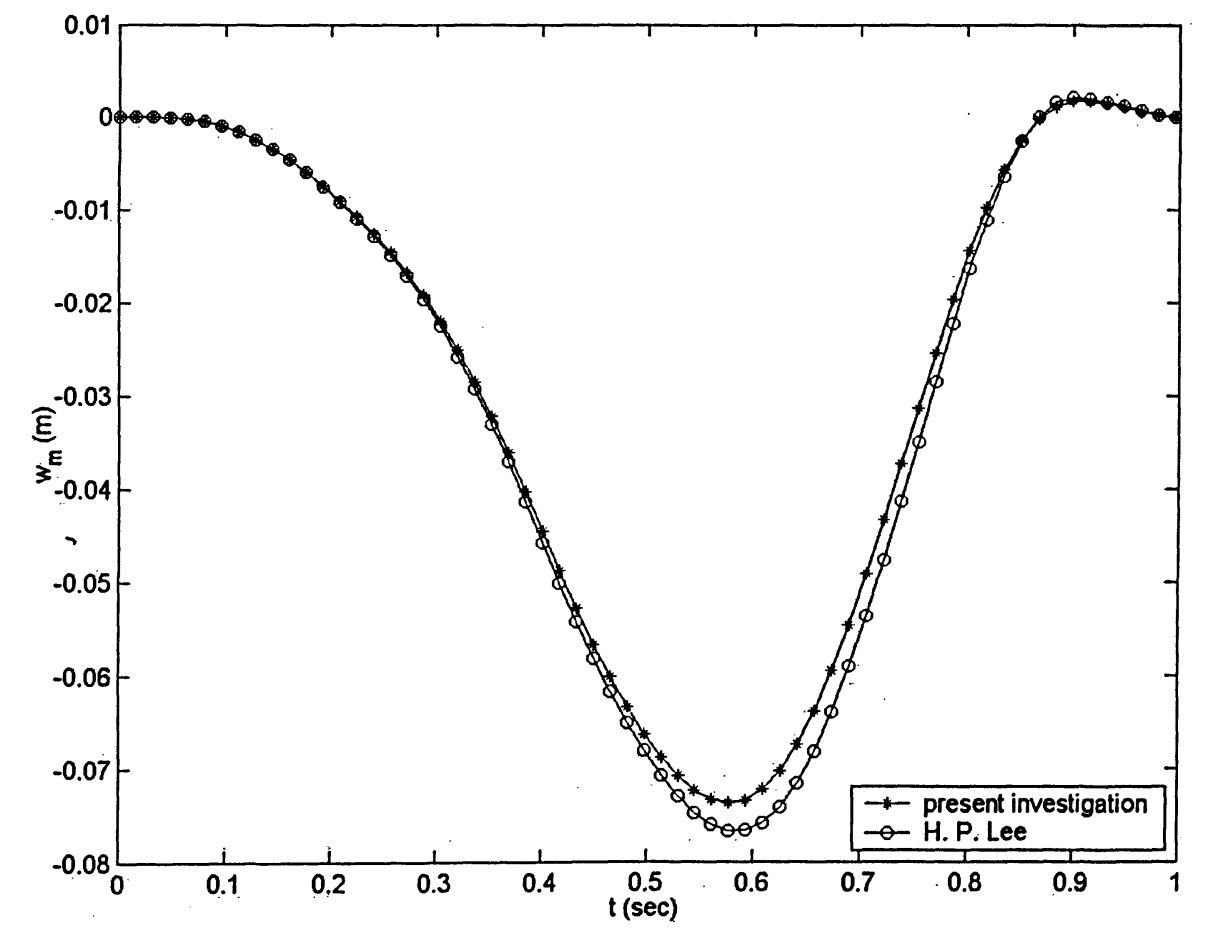

Figure 6 Effect of the representation of the gyroscopic forces for a clamped-clamped beam 


\subsubsection{Effect of Beam Second Moment of Area}

The effect of the second moment of area is examined in this subsection. Three sets of cross-sectional dimensions are considered: $\{0.4 \times 0.4\},\{0.2 \times 0.8\}$ and $\{0.8 \times 0.2\}$. The first entry is the width and the second is the height of the cross section. The displacements of the traversing mass for both the simply-supported and clamped-clamped beam boundary conditions with the linear strain-displacement assumption are illustrated in Figs. 7 and 8, respectively. The results indicate the independence of displacements on the second moment of area of the beam for a given set of boundary conditions. It is, however, not unexpected and the figures have been included solely for completeness. This is because, although the $K_{1}$ term in Eqn. (14) is influenced by the beam second moment of area, the value of the ratio EI / $\rho$ A remains constant.

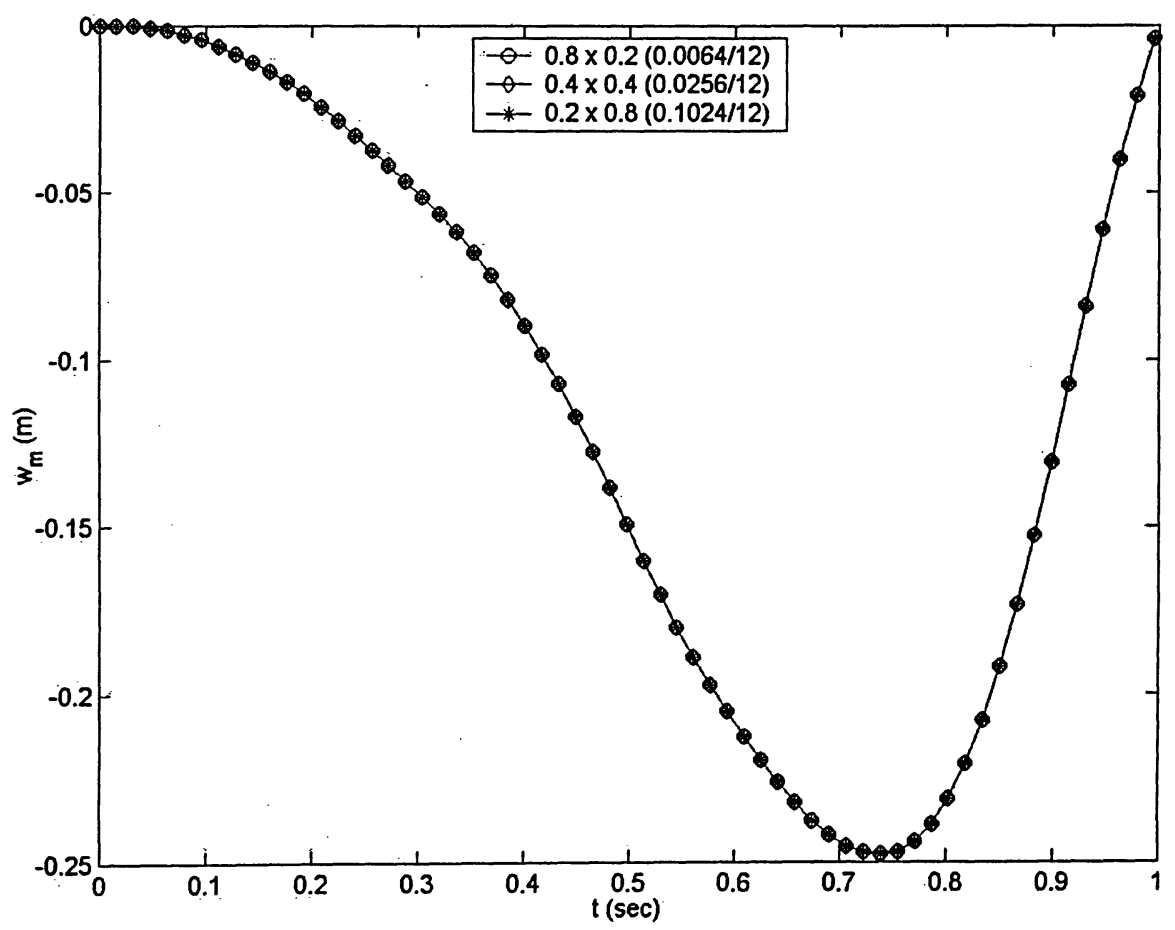

Figure 7 The linear displacement of the traversing mass on a simply-supported beam 


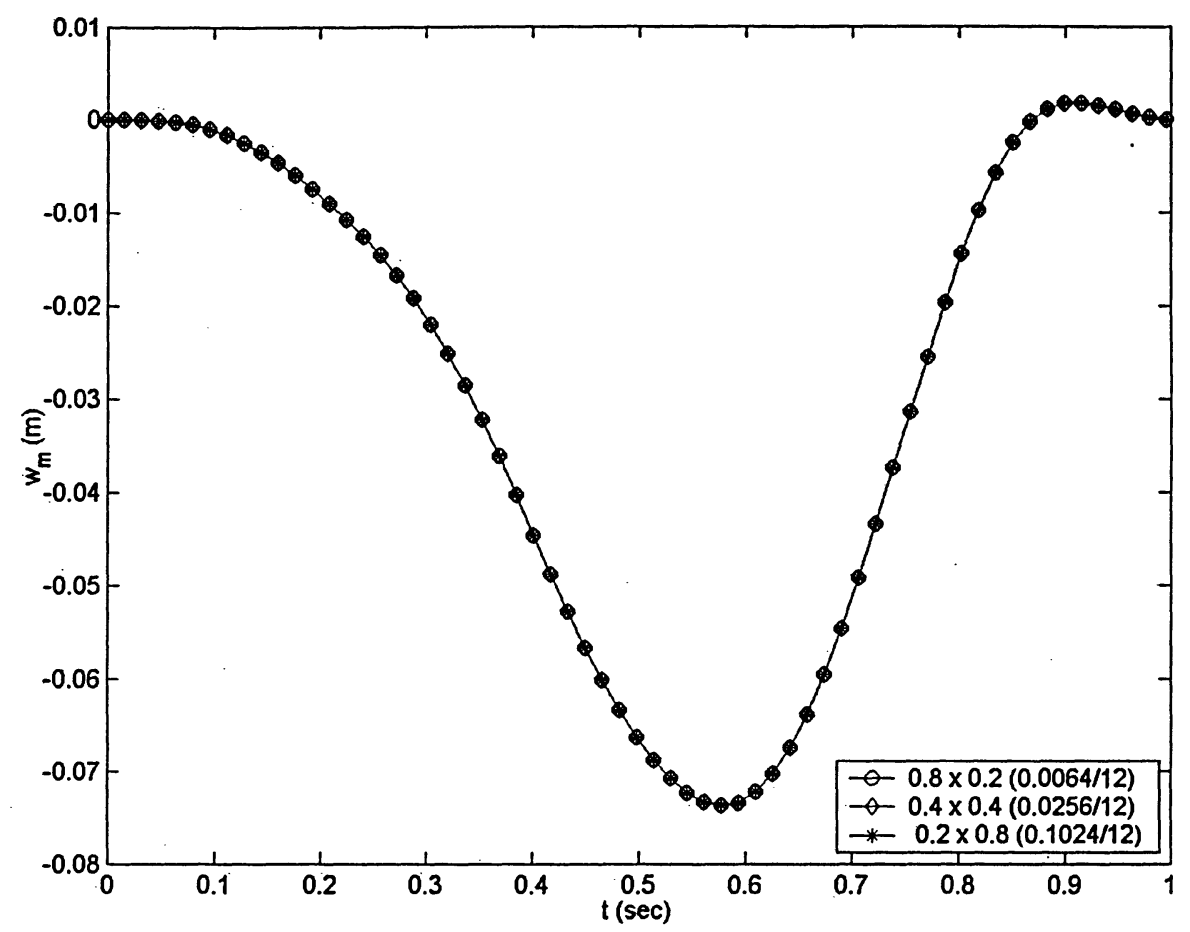

Figure 8 The displacement of a traversing mass on a clamped-clamped beam

The corresponding results for the assumption of nonlinear strain-displacement relation for a simply-supported beam are depicted in Figs. 9 and 10. The former is a traversing force scenario and the latter refers to a traversing mass. Unlike the observations in the preceding linear scenario, the peak displacement and its time of occurrence are observed to increase with increasing beam second moment of area. The increase in the peak displacement can be understood by observing that the value of the ration $E / \rho$ which appears in the $K_{4}$ term of Eqn. (15) decreases with increasing beam second moment of area. Therefore, the net effect on the effective stiffness is stiffening with decreasing beam second moment of area. 


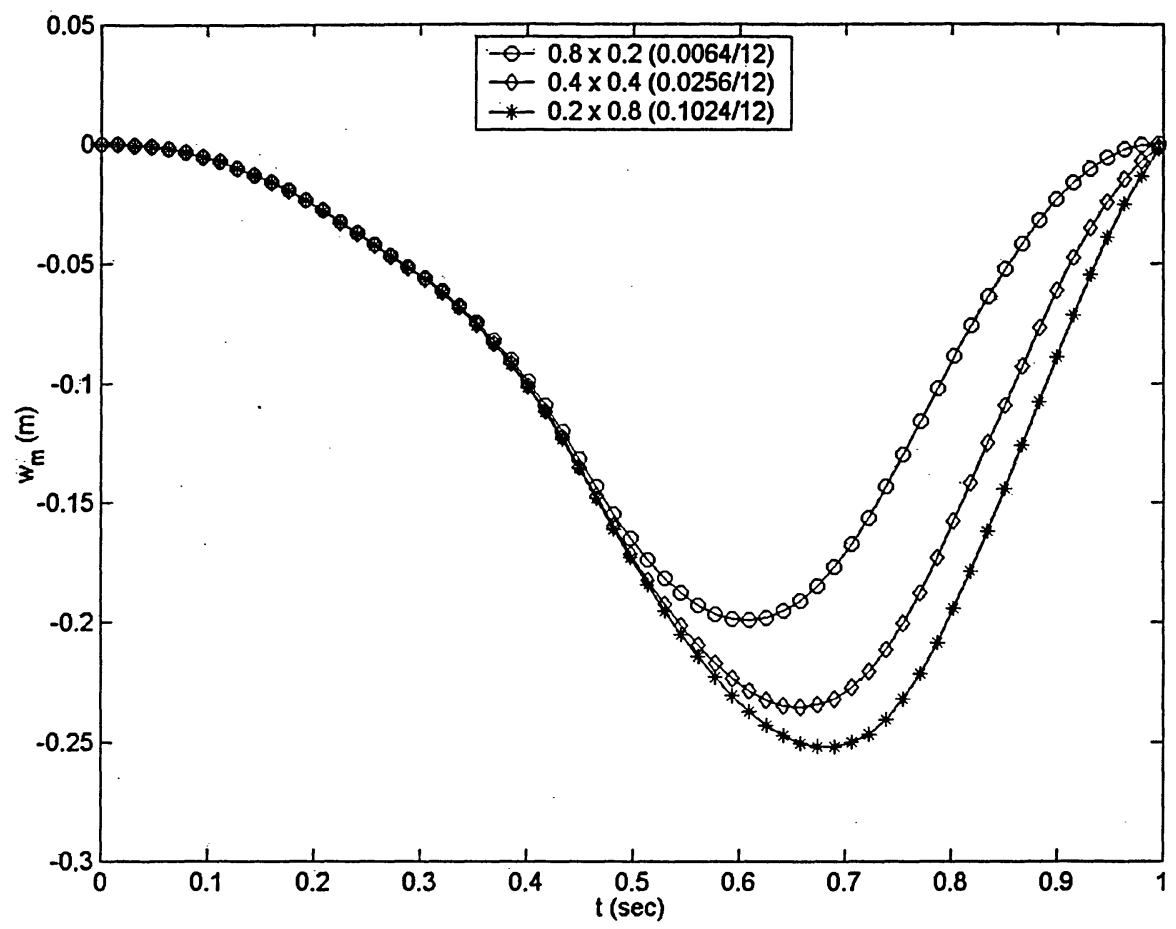

Figure 9 The nonlinear displacement of a traversing force on a simply-supported beam

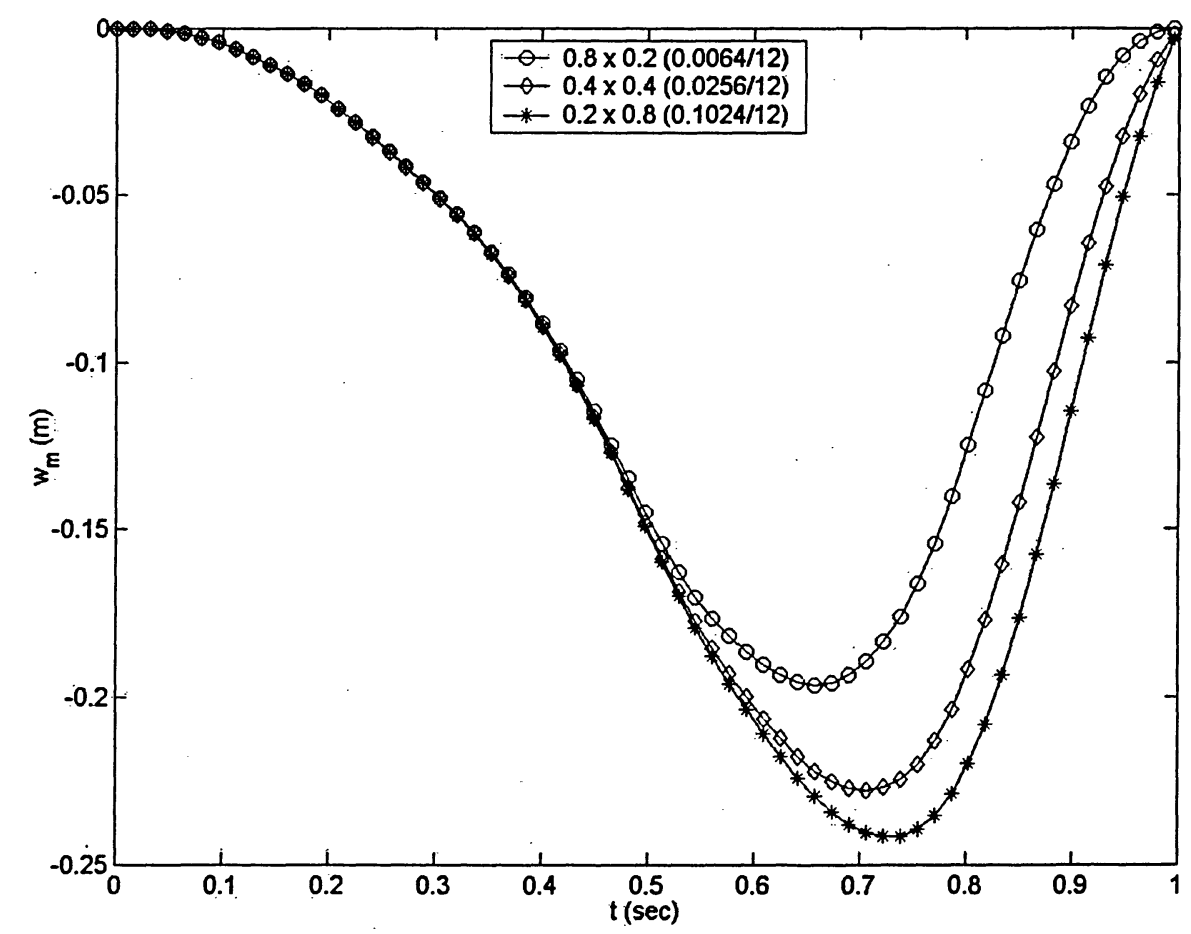

Figure 10 The nonlinear displacement of a traversing mass on a simply-supported beam 


\subsubsection{Effect of Traversing Velocity}

The effect of the traversing velocity is investigated in this subsection. The results for the case of linear strain-displacement assumptions are depicted in Figs. 11 and 12, and those for the nonlinear strain-displacement case are illustrated in Fig. 13. Both simply-supported and clamped-clamped beam boundary conditions are investigated in the linear analysis, but only the simply-supported beam is examined in the nonlinear analysis. The traversing velocity is represented as a fraction of the critical velocity, which is calculated as

$$
\dot{\xi}=\alpha \dot{\xi}_{\mathrm{cr}} \quad \text { and } \quad \dot{\xi}_{\mathrm{cr}}=\sqrt{\frac{\mathrm{EI}}{\rho \mathrm{AL}^{4}}} \pi \mathrm{L}
$$

The value of the critical velocity is computed as is $8.6898 \mathrm{~m} / \mathrm{s}$.

A general trend from the results is that there exists a boundary condition dependent critical velocity fraction below which the peak displacement increases with increasing fraction, and above which it decreases with increasing fraction. Further, there is also a boundary condition dependent critical velocity fraction below which the analysis effectively collapses to a quasi-static condition.

Perhaps it is worth mentioning that the above observations also hold for the case of nonlinear strain-displacement relations, as can be inferred from Fig. 13. 


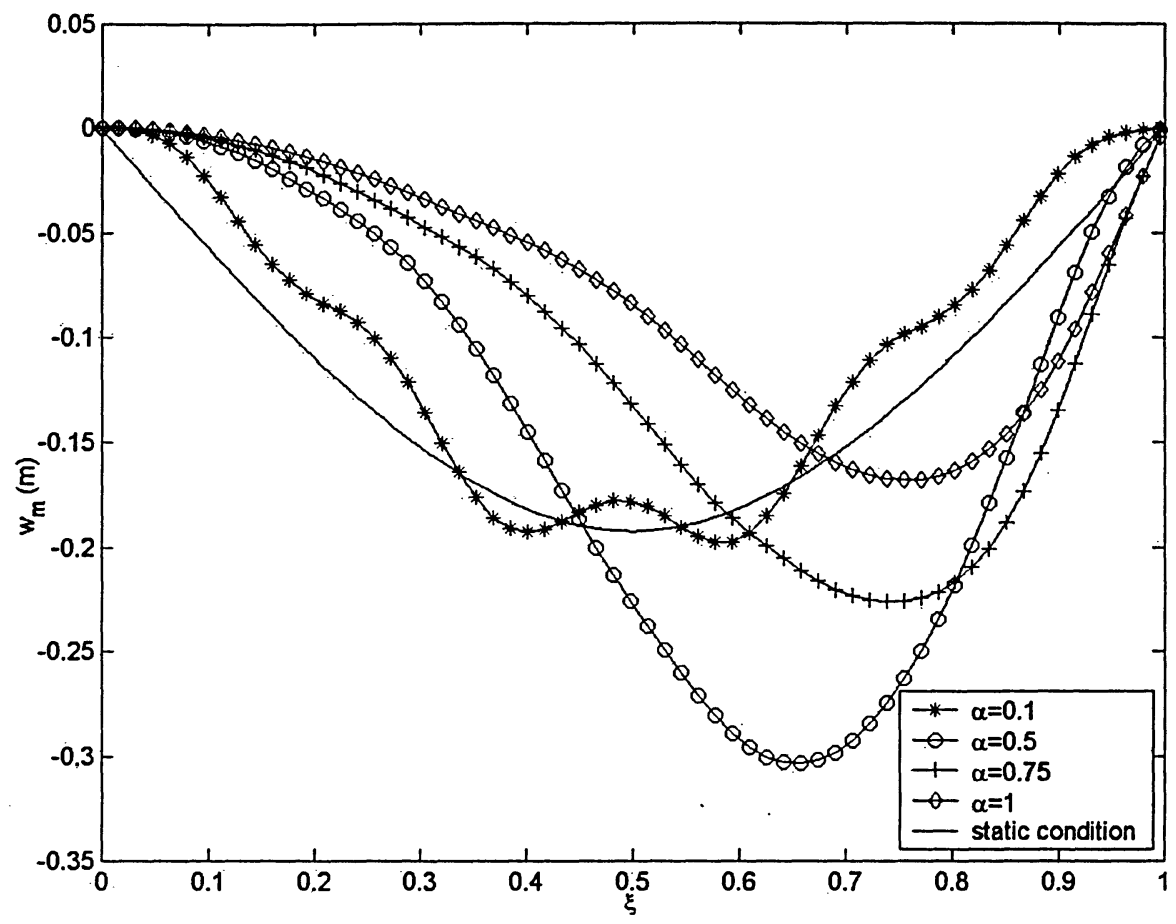

Figure 11 The linear displacement of a traversing mass on a simply-supported beam

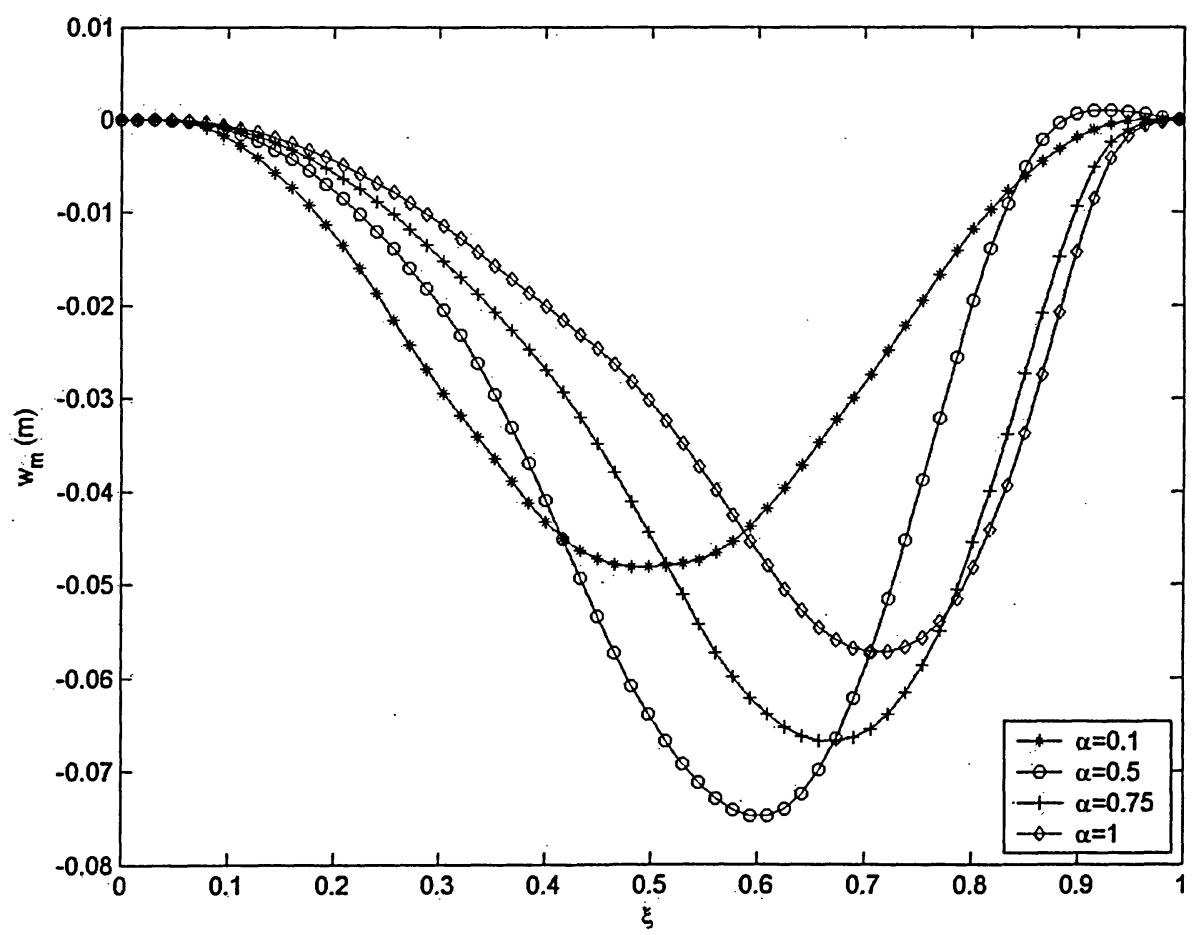

Figure 12 The linear displacement of a traversing mass on a clamped-clamped beam 


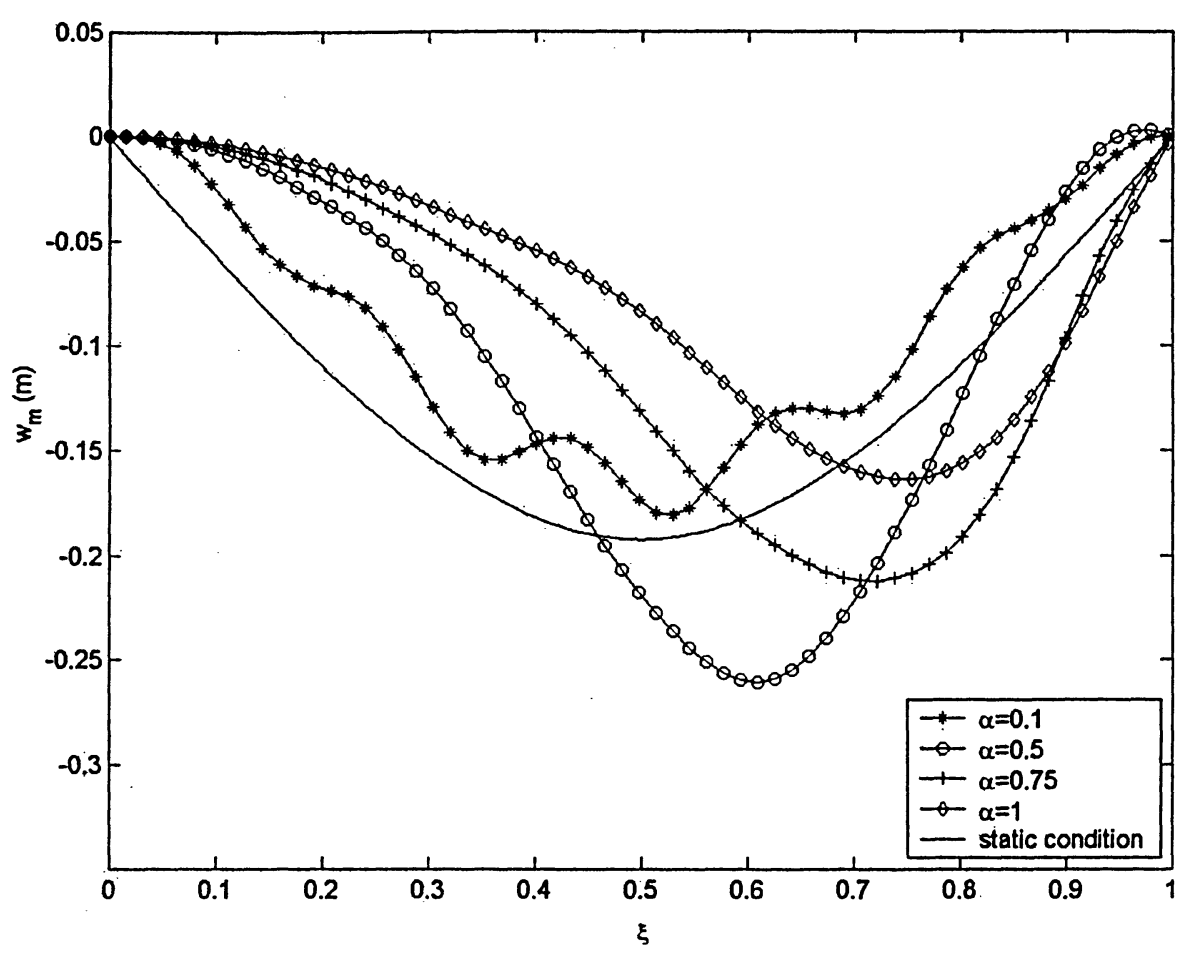

Figure 13 The nonlinear displacement of a traversing mass on a simply-supported beam

\subsubsection{Effect of Velocity Square}

As noted in Section 5.1.1, during the process of validating the formulation and the computer codes developed for this project, some investigators ignore the square of the traversing velocity in order to make the mathematics more tractable. The problem with this is that no convincing reasons are often provided, especially when the velocities are so selected such that the length of the beam is traversed in a second. The object of this subsection is to examine, via numerical simulation, the existence of a threshold traversing velocity below which the assumption is valid. Figs. 14 and 15 are the displacements for both linear and nonlinear simply-supported beams with and without the velocity square term $\dot{\xi}^{2}$. The critical velocity is determined from Eqn. (21). 
As expected, the effect of ignoring $\dot{\xi}^{2}$ is negligible for a very small critical velocity ratio, about 0.1 in the results reported. The differences are most amplified around the peak displacements. In fact, ignoring the square velocity term underestimates the peak displacement. This would imply that the term modulates the stiffness so as to create a softening. Further, it is noted that the velocity used in the studies reported in Ref. [6] corresponds to a critical velocity ratio of 0.69 , which is much greater than 0.25 , and hence explains the discrepancy in the results reported in Fig. 3.

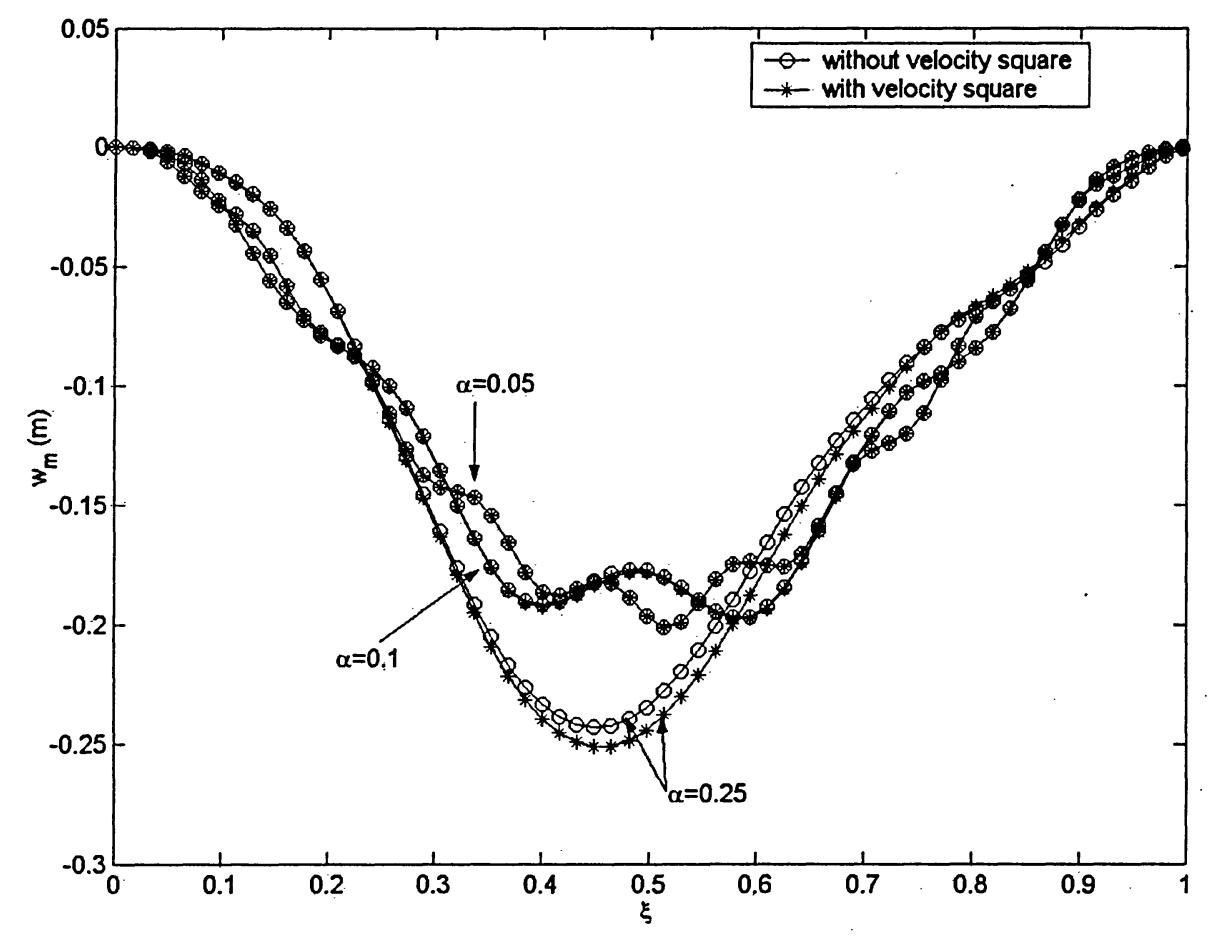

Figure 14 The linear displacement of a traversing mass on a simply-supported beam 


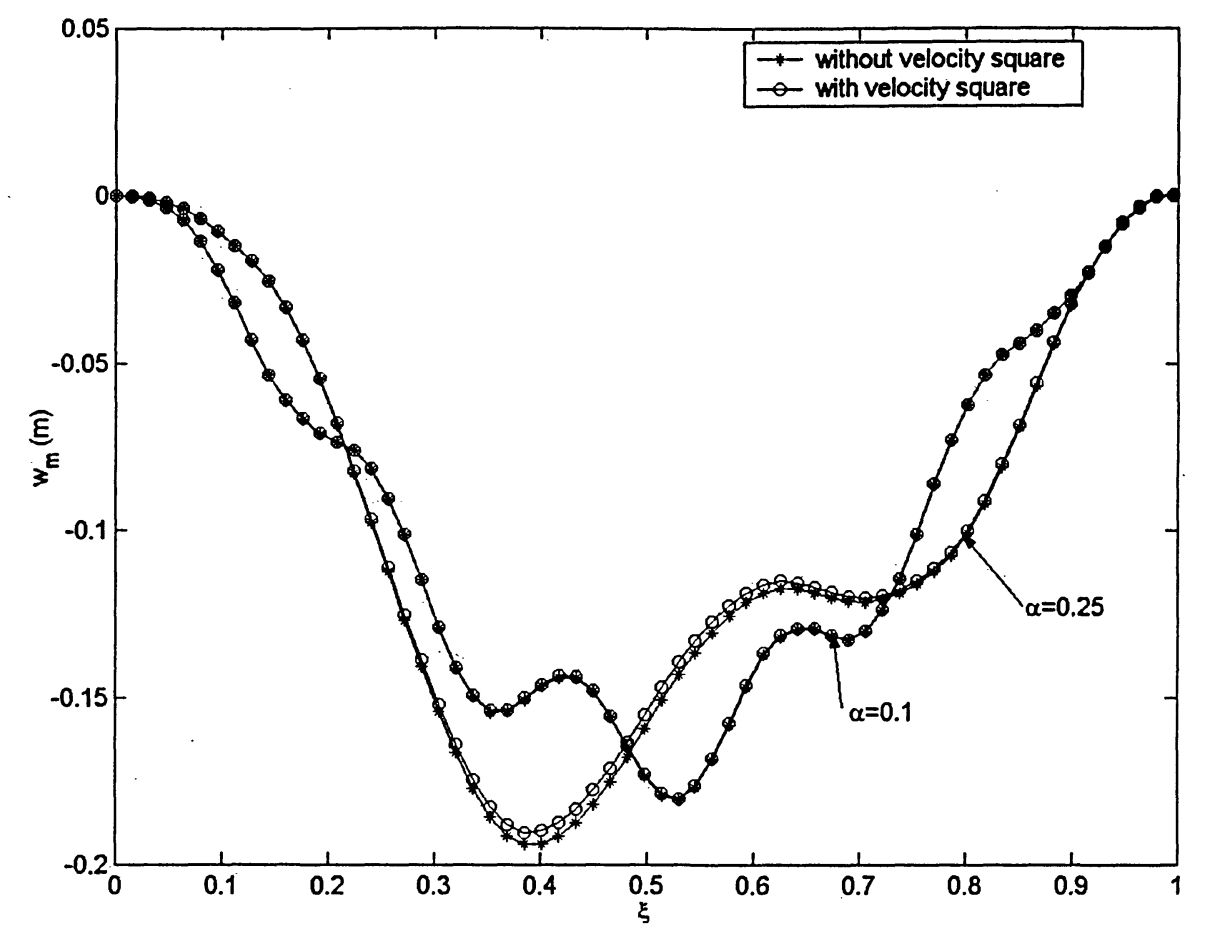

Figure 15 The nonlinear displacement of a traversing mass on a simply-supported beam 


\section{Chapter 6}

\subsection{Conclusion}

The objective of this study is to investigate the response of an Euler-Bernoulli beam under a constant velocity traversing load. The load is either a point force or point mass, and the boundaries of the beam are constrained as simply-supported or clamped-clamped. The system governing equations are derived using the extended Hamilton's principle. Both linear and nonlinear strain-displacement relations are assumed. However, the clamped-clamped boundary condition is only simulated with the former assumption.

The fidelity of the developed equations is confirmed by reproducing the results in the literature. Some inaccuracies in some of the studies in the literature are observed during this exercise and their consequences are noted. Following the confirmation of the fidelity and validity of the model and corresponding governing equations, the effect of some parameters on the system response are investigated. Specifically, these parameters are the traversing velocity, second moment of area of the beam, the centrifugal forces, and the velocity square.

The following observations are inferred from the study:

1. The displacement of the moving force model, for both simply-supported and clampedclamped boundary conditions, is not necessarily an upper bound when compared against that from the corresponding moving mass model.

2. The displacement of the traversing load for a clamped-clamped boundary condition is significantly lower than for a simply-supported boundary condition. This is attributable to the higher stiffness induced by the former. 
3. The maximum displacement of the traversing load does not always occur when the load is at the mid-span location of beam. This behaviour is a consequence of both the reflected waves from the boundary of the beam and the velocity of the traversing load.

4. The second moment of area has no effect on the linear strain-displacement scenario, but has a significant influence on the displacement of the traversing load for a nonlinear straindisplacement scenario. Specifically, the peak displacement and its time of occurrence increase with increasing beam second moment of area. Hence, the stiffness increases with decreasing second moment of area.

5. The exclusion of gyroscopic forces in the governing equation of motion overestimates the peak displacement of the traversing mass for both simply-supported and clamped-clamped boundary conditions.

6. The exclusion of the convective terms makes the governing equation of motion mathematically more tractable. Although a good displacement profile is generally observed, there are differences in the displacements at any given time. Further, for the parameters investigated, the magnitudes of the peak displacement are relatively equal, but they are observed at different times.

\subsection{Future Work}

This study can be advanced by examining the following:

1. Accelerating traversing load scenarios.

2. The effect of a nonlinear strain-displacement relation assumption for the clamped-clamped boundary conditions case.

3. Other types of loads such as distributed loads.

4. Other boundary conditions such as cantilevered or clamped-free. 
5. Other beam models such as the Rayleigh beam model and the Timoshenko beam. The former includes rotary inertia while the latter includes both rotary inertia and shear effects. 


\section{References}

1. Stokes, G. G., "Discussion of a Differential Equation Relating to the Breaking of Railway Bridges", Mathematical and Physical Papers, Vol. 2 (1883), 178-220

2. Frýba, L., Vibration of Solids and Structures Under Moving Loads, Thomas Telford, London, 1999

3. Rao, G. V., "Linear Dynamics of an Elastic Beam Under Moving Loads", Journal of Vibration and Acoustics, 122 (2000), 281-289

4. Atkin, J. E., and Mofid, M., "Numerical Solution for Response of Beams with Moving Mass", Journal of Structural Engineering, 115-1 (1989), 120-131

5. Hamada, T. R., "Dynamic Analysis of a Beam Under a Moving Force: A Double Laplace Transform Solution", Journal of Sound and Vibration, 74-2 (1981), 221-233

6. Sadiku, S., and Leipholz, H. H. E., "On the Dynamics of Elastic Systems with Moving Concentrated Masses", Ingenieur-Archiv, 57 (1987), 223-242

7. Stanisic, M. M., Euler, J. A., and Montgomery, S. T., "On a Theory Concering the Dynamical Behaviour of Structures Carrying Moving Masses", Ingenieur-Archiv, 13 (1974), 295-305

8. Stanisic, M. M., "On a New Theory of the Dynamic Behaviour of the Structures Carrying Moving Masses", Ingenieur-Archiv, 55 (1985), 176-185

9. Lee, H. P., "The Dynamic Response of a Timoshenko Beam Subjected to a Moving Mass", Journal of Sound and Vibration, 198-2 (1996), 249-256

10. Lee, H. P., "Transverse Vibration of a Timoshenko Beam Acted on by an Accelerating Mass", applied Acoustics, 47-3 (1996), 319-330

11. Lin, Y. H., "Vibration Analysis of Timoshenko Beams Traversed by Moving Loads", Journal of Marine Science and Technology, 2-1 (1994), 25-35

12. Mackerich, S., "Response of a Beam to a Moving Mass", Journal of Acoustical Society of America, 92-2 (1992), 1766-1769

13. Yavari, A., Nouri, M, and Mofid, M., "Discrete Element Analysis of Dyanmic Response of Timoshenko Beams Under Moving Mass", Advances in Engineering Software, 33 (2002), 143-153

14. Lee, U., "Revisiting the Moving Mass Problem: Onset of Separation Between the Mass and Beam", Journal of Vibration and Acoustics, 118 (1996), 516-521 
15. Rieker, J. R., Trethewey, M. W., "Finite Element Analysis of an Elastic Beam Structure Subjected to a Moving Distributed Mass Train", Mechanical System and Signal Processing, 13-1 (1999), 31-51

16. Rieker, J. R., Lin, Y. H., and Trethewey, M. W., "Discretization Considerations in Moving Load Finite Element Beam Models", Finite Element in Analysis and Design, 21 (1996), 129-144

17. Wu, J. J., Whittaker, A. R., and Cartmell, M. P., "Dynamic Response of Structures to Moving Bodies Using Combined Finite Element and Analytical Methods", International Journal of Mechanical Sciences, 43 (2001), 2555-2679

18. Inman, D. J., "Engineering Vibration, $2^{\text {nd }}$ Edition”, Prentice-Hall Inc, New Jersey, 2001

19. Lee, H. P., "On the Dynamic Behaviour of a Beam with an Accelerating Mass", Archive of Applied Mechanics, 65 (1995), 564-571

20. Gbadeyan, J. A., Oni, S. T., "Dynamic Behaviour of Beams and Rectangular Plates under Moving Loads", Journal of Sound and Vibration, 182(5) (1995), 677-695 